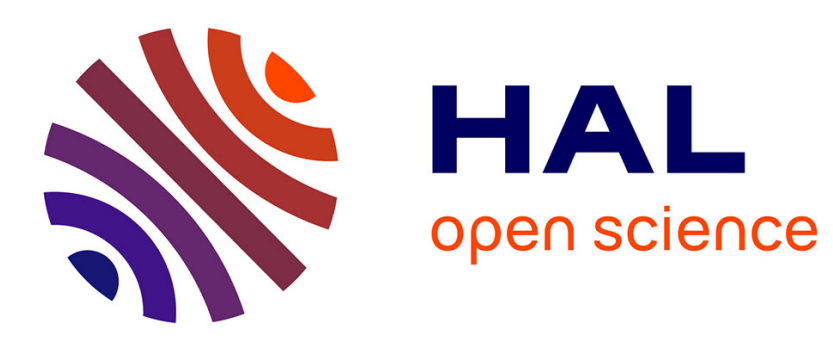

\title{
Transmission electron microscopy of cellulose. Part 2: technical and practical aspects
}

\author{
Yu Ogawa, Jean-Luc Putaux
}

\section{To cite this version:}

Yu Ogawa, Jean-Luc Putaux. Transmission electron microscopy of cellulose. Part 2: technical and practical aspects. Cellulose, 2019, 26 (1), pp.17-34. 10.1007/s10570-018-2075-x . hal-02106166

\section{HAL Id: hal-02106166 \\ https://hal.science/hal-02106166}

Submitted on 10 May 2021

HAL is a multi-disciplinary open access archive for the deposit and dissemination of scientific research documents, whether they are published or not. The documents may come from teaching and research institutions in France or abroad, or from public or private research centers.
L'archive ouverte pluridisciplinaire HAL, est destinée au dépôt et à la diffusion de documents scientifiques de niveau recherche, publiés ou non, émanant des établissements d'enseignement et de recherche français ou étrangers, des laboratoires publics ou privés. 


\title{
Transmission electron microscopy of cellulose. Part 2: Technical and practical aspects.
}

\author{
Yu Ogawa and Jean-Luc Putaux* \\ Univ. Grenoble Alpes, CNRS, CERMAV, F-38000 Grenoble, France
}

\$yu.ogawa@cermav.cnrs.fr - ORCID: 0000-0003-0677-7913

* corresponding author: jean-luc.putaux@cermav.cnrs.fr - ORCID: 0000-0002-9760-5369

Published in: Cellulose 26 (2019), 17-34

DOI: 10.1007/s10570-018-2075-x 


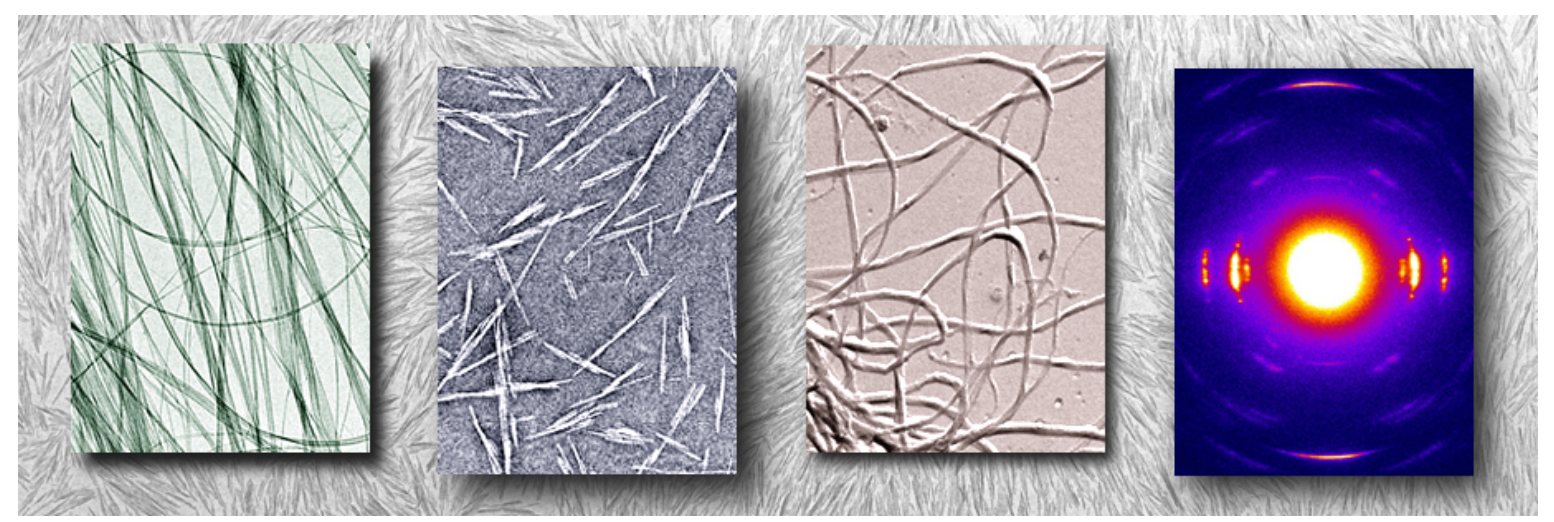

\begin{abstract}
Transmission electron microscopy (TEM) has played a significant role in the characterization of cellulosic materials, especially the so-called "nanocelluloses" (nanofibers and nanocrystals), from visualizing nanoscale morphologies to identifying crystal structures. With scientific and industrial interest in nanocelluloses rapidly increasing, this technique is more important than ever for scientists, engineers and students. Mastering TEM techniques for cellulosic materials is not trivial for a number of reasons, the main one being the high sensitivity of cellulose crystals to electron beam damage. In this contribution, practical aspects of sample preparation, contrast enhancing protocols as well as specific imaging and diffraction techniques are described to facilitate the morphological and structural characterization of cellulose by TEM in imaging and electron diffraction modes. We especially emphasize the importance of controlling the radiation dose to record well-resolved images of cellulose crystals with meaningful structural detail.
\end{abstract}

Keywords: cellulose; nanocellulose; transmission electron microscopy; electron diffraction

\title{
Disclaimer
}

The mention of trademarks or commercial products in this article is solely for information purpose. It is not exhaustive and mostly aims at providing examples of sample preparation materials and methods. It does not imply any affiliation of the authors with the aforementioned companies. 


\section{Introduction}

The development of bio-based products is currently triggering a very strong interest throughout the world, the goal being the processing of new advanced materials showing a minimum environmental impact. In this quest, cellulose and in particular nanocelluloses stand out as candidates of great potential (Klemm et al. 2005; Dufresne 2013; Kargarzadeh et al. 2018; Klemm et al. 2018). Indeed, cellulose is abundant, relatively cheap, readily available in large quantities, non-toxic and biodegradable. Cellulose is found in the cell walls of most plants and some algae, but also occurs in a selection of living creatures, such as some bacteria, fungi, a few amoebae and some sea animals (Brown 1996). The basic structural element common to all the sources mentioned above, and with only a very few exceptions, is the microfibril, more recently renamed nanofibril (Nishiyama 2009; Chinga-Carrasco 2011). This ubiquitous element results from the coordinated action of the biosynthesis of cellulose molecules, their spinning through an array of protein complexes acting as bio-spinnerets, and their subsequent quasi-instantaneous crystallization (Brown 1996). In fact, the bioproduced nanofibrils are very long slender crystalline filaments with constant diameters ranging from around $2 \mathrm{~nm}$ to $25 \mathrm{~nm}$, depending on the sample origin. As the nanofibrils are endowed with strong mechanical properties in the range of 115-140 GPa for their modulus (Nishiyama 2009) and up to 2-6 GPa for their strength (Saito et al. 2013), they can find applications as matrix reinforcements in nanocomposites (Oksman et al. 2016). When heated in strong aqueous acid solutions, cellulose nanofibrils break down into shorter nanocrystals, sometimes called whiskers (or nanowhiskers) due to their needle-like aspect. These monocrystalline elements have the same diameter as the parent nanofibril but their length varies with the sample origin, from a few tens of nanometers up to several microns (Chauve et al. 2014). Due to their high aspect ratio and inherent strong mechanical characteristics, these nanocrystals exhibit interesting properties. Besides their use as mechanical reinforcement in nanocomposites, they find applications in gels, aerogels and in suspensions, like liquid crystalline self-organization and iridescence when concentrated (Eichhorn 2011; Habibi et al. 2010; Lin and Dufresne 2014; Reid et al. 2017).

To grasp the full potential of nanocelluloses, either as nanofibrils (CNFs) or nanocrystals (CNCs), it is important to describe their ultrastructure with precision. Whereas $\mathrm{X}$-ray and neutron scattering spectra together with spectroscopic data give average details of the structure and morphology of the various nanocelluloses, their fine local ultrastructure needs to be described with high-resolution microscopy techniques, using either atomic force 
microscopes (AFM) or transmission electron microscopes (TEM). While both types of instruments provide informative details about the morphology of nanocelluloses (Skogberg et al. 2017; Tibolla et al. 2018; Usov et al. 2015; Zhang et al. 2018), the recording of meaningful AFM images appears to be somewhat easier, giving a precise measurement of the particle thickness while being less precise for their width (Lahiji et al. 2010). TEM presents a strong advantage for cellulose imaging since it provides not only standard images but also local electron diffraction diagrams, together with diffraction contrast images, using the diffracted beams to reveal specific crystalline details of nanocellulose. However, despite the potential of TEM, the successful recording of images of cellulose may be hampered by the damage created by the electron beam.

Part 1 of this two-part article on TEM of cellulose is an historical account of the contribution of transmission electron microscopy and electron diffraction to the knowledge of the cellulose ultrastructure (Ogawa et al. 2019). The purpose of this second part is to share our expertise in the recording of TEM images, electron diffraction diagrams and diffraction contrast images of cellulose, and complement recent "recipe" papers which have described some of the techniques used to record TEM images of CNCs (Kaushick et al. 2015; Foster et al. 2018; Jakubek et al. 2018; Stinson-Bagby at al. 2018). In particular, we show that careful control of the electron beam intensity is important for recording well-resolved images of unshadowed or unstained nanocelluloses allowing one to visualize meaningful details while keeping the diffraction information.

\section{Sample preparation}

Preparation of TEM samples is crucial and often constraining in order to facilitate observation of nanocellulose and record meaningful images. The specimens must be thin enough to be (at least partially) transparent to electrons. The images then show both the contours and projected volume of the specimen crossed by the electrons. The limiting thickness depends on the energy of the incident electrons and on the atomic number and density of the material. Ideally, for organic polymers, the thickness should be lower than 0.5 $\mu \mathrm{m}$. That of individual CNFs and CNCs, of the order of a few nanometers, is well below this limit and TEM specimens of nanocellulose are often prepared from very dilute suspensions (typically 0.001-0.01 wt\%). However, for bulk materials, such as wood (Reza et al. 2015), plant cell walls, algae or nanocomposite materials, specific microtomy procedures are required to obtain ultrathin sections. 


\subsection{Grids and supporting films}

TEM specimens are classically prepared on thin metallic grids, $3.05 \mathrm{~mm}$ in diameter. A large variety of TEM grids is available, with square, rectangular or hexagonal meshes around a few tens of micrometers. The metal can be selected depending on the application and preparation procedure. 200-400 square mesh copper grids are the cheapest and the most widely used. Gold or nickel grids should be preferred when copper may be degraded by the deposited liquid (in the case of acidic media, for example). Amorphous carbon is the most commonly used supporting film, thanks to its transparency to electrons, good mechanical stability and resistance to chemicals. Carbon-coated grids are commercially available but carbon films can also be prepared in the laboratory. In one procedure, carbon is evaporated under vacuum onto cleaved mica and the resulting thin films (typically 5-20 nm thick) are floated on water and "fished" on TEM grids. In another protocol, a nitrocellulose collodion thin film is cast on water and then fished on TEM grids, followed by carbon vacuum evaporation and collodion dissolution in acetone vapors (Harris 1997). Other materials have been tested as supporting films, like Formvar which is less electron-transparent than carbon and not as stable at high magnification. Hydrophilic silicon monoxide (Kaushik et al. 2014), silica $\left(\mathrm{SiO}_{2}\right)$ and silicon nitride $\left(\mathrm{Si}_{3} \mathrm{~N}_{4}\right)$ films are also commercially available (NanoGrids ${ }^{\mathrm{TM}}$ from Dune Sciences).

\subsection{Glow discharge}

Nanocellulose TEM samples must be prepared so as to avoid aggregation. The nanoobjects have to be well-dispersed and individual to determine, for example, the CNC particle size distribution. If aqueous suspensions are directly deposited on the initially hydrophobic supporting carbon film, the liquid will likely air-dry in the form of droplets in which the material will accumulate as the liquid evaporates. The so-called glow discharge procedure can be used as a pretreatment before sample deposition (Dubochet et al. 1971; Aebi and Pollard 1987; Harris 1997). The carbon-coated grids are placed inside the chamber of a dedicated unit (e.g. automated systems like GloQube ${ }^{\mathrm{TM}}$ from Quorum Technologies, ELMO ${ }^{\mathrm{TM}}$ from Agar Scientific or easiGlow ${ }^{\mathrm{TM}}$ from Pelco) and submitted to a mild plasma cleaning under reduced air pressure (0.1 - 1.0 mbar) during a few seconds. The treated carbon surface becomes (and remains) hydrophilic for several minutes allowing aqueous suspensions to spread over the whole grid. As charges are also generated on carbon upon treatment, the particles can adsorb on the surface, which limits their movement upon drying. The factory settings of the commercial systems generally yield negatively charged hydrophilic surfaces but positive charges and/or hydrophobic surfaces can be produced using additional agents (Dubochet et al. 1971). 
Although different methods to hydrophilize the carbon-coated grids have been proposed, such as ultraviolet light irradiation (Walker et al. 1985) and pretreatment with surfactants, those methods are generally less reproducible or more time-consuming compared to the glow discharge technique. A feasible alternative has recently been reported using bovine serum albumin (BSA) to prevent nanoparticles aggregating during air-drying (Michen et al. 2015).

\subsection{Contrast-enhancement techniques during sample preparation}

Polymer nanoparticles, and nanocelluloses in particular, being constituted of light atoms, generally present a rather low electron scattering contrast. Moreover, in order to visualize details at the nanoscale, high magnifications are used, resulting in a fast degradation of the particles and in an even lower contrast. Several techniques can be implemented during the preparation of the specimens to enhance contrast when observed by TEM, namely negative staining and metal shadowing.

\subsubsection{Negative staining}

Typically, a drop of saturated heavy atom salt in aqueous solution is deposited on the specimen. Upon drying, a thin layer of concentrated stain forms a cast around the nanoparticles. The so-called negative effect in the image thus comes from the fact that the lighter nanocellulose particles appear as clear objects on a darker background and their contours are clearly delineated by an electron-dense outline (Harris 1997). When observed at a higher magnification, even though cellulose is indeed rapidly damaged by the electron beam, the heavy atom cast is stable, revealing fine details of the surface topography. However, care must be taken to evaluate possible artifacts due to staining such as stain heterogeneity on the surface of the particles, excessive granularity interpreted as a cellulose nanostructure (Manley 1971), or underestimation of the particle size due to overlapping (Preston 1971). In the past decades, the most commonly used negative stain has been aqueous uranyl acetate $(2 \mathrm{wt} \%)$, as well as phototungstic acid or ammonium molybdate. Even though uranyl acetate can be easily handled, with the necessary precautions due to its acidity and low radioactivity, this product will rapidly disappear from the catalogues. A significant price increase is expected after recent regulations have been enforced regarding the handling of radioactive products. Therefore, new ready-to-use negative stain solutions that will replace uranyl acetate are now commercially proposed, such as Uranyless ${ }^{\mathrm{TM}}$ (that contains lanthanides, from Delta Microscopies) or NanoW ${ }^{\mathrm{TM}}$ (methylamine tungstate compound, from Nanoprobes). 
Practically, to achieve a satisfactory negative staining of nanocellulose samples, i) the supporting carbon film must be glow-discharged before the nanoparticles deposition, and ii) the negative stain must be deposited before complete drying of the deposited specimen. After a few minutes, the stain in excess can be gently blotted off with filter paper and the residual thin liquid stain film allowed to dry. A preparation of tunicate CNCs negatively stained with uranyl acetate is shown in Figure 1a, but images recorded on various sources of nanocellulose can be found in the literature (Saito et al. 2006; Elazzouzi-Hafraoui et al. 2008; Brito et al. 2012; Chauve et al. 2014; Brinkmann et al. 2016; Flauzino-Neto et al. 2016; Tanaka et al. 2017).

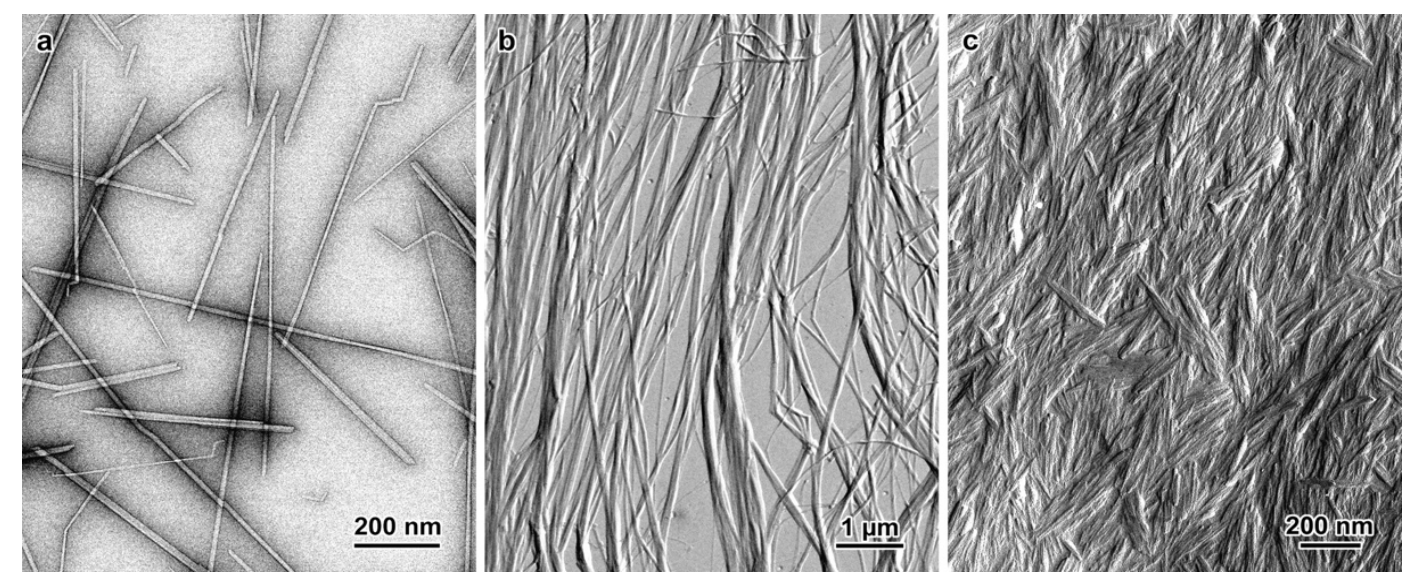

Figure 1. Contrast-enhancement techniques for TEM specimen preparation: a) tunicate CNCs negatively stained with uranyl acetate; b) Valonia cellulose nanofibrils directionally shadowed with W/Ta alloy; c) surface replica of a freeze-fractured concentrated suspension of cotton CNCs (courtesy of Elazzouzi-Hafraoui, CERMAV).

\subsubsection{Metal shadowing and freeze fracture}

Metal shadowing has been used very early on to enhance the contrast of cellulose preparations for TEM: wood and cotton microfibrils (Rånby 1952a), bacterial and tunicate CNCs (Rånby 1952a; Rånby 1952b), ramie and cotton CNCs (Mukherjee and Woods 1953). Metal (generally tungsten/tantalum alloy or platinum/carbon) is evaporated under vacuum on the sample at a given incidence angle, using an electron gun or specific electrodes. The directional and selective accumulation of metal on the sample results in a grazing light effect that enhances the topographic details of the specimen with very high contrast. At higher magnification, the electron-dense metal-rich regions are stable even when the cellulose particles are damaged by the electron beam. However, the image resolution becomes limited by the granularity of the applied metal cast and the apparent width of the particles can be increased by the shadowing layer. The example of Valonia CNFs directionally shadowed with $\mathrm{W} / \mathrm{Ta}$ is shown in Figure 1b. 
The freeze-fracture technique can be used in the specific case of concentrated liquids or gel-like nanocellulose suspensions (Robards and Sleytr 1985) as well as for biological cellulosic tissues (Kimura and Itoh 2004). Briefly, a specimen is fast frozen under vacuum and fragmented by a sharp knife. The freshly fractured surfaces are then directionally shadowed with a thin layer of evaporated platinum-carbon, and consolidated with an additional layer of carbon to form a replica of the fractured surface. Frozen cellulose suspensions then melt upon warming up and the replica can simply be washed with water. With freeze-fractured biological tissues, the replicas need to be disencrusted with strong acid, such as sodium dichromate/sulfuric acid solution, before extensive washing with water. The metal replica is then fished on a carbon-coated grid and observed by TEM. This technique thus provides an indirect view of the fracture surface topography with a very high contrast, as illustrated in Figure 1c in the case of a concentrated suspension of cotton CNCs.

\subsection{Cryo-transmission electron microscopy}

Cryo-TEM has been developed to observe nanoparticle suspensions while avoiding possible artefacts induced by drying and/or staining (such as deformation, degradation, aggregation, uniplanar orientation or buffer salt crystallization) (Dubochet et al. 1988). Since the particles are embedded in a thin electron-transparent film of vitreous ice during the observation, this technique is particularly helpful for soft or liquid colloidal nanoparticles whose morphology or structure would be affected by air-drying (deformation due to capillary forces, decrystallization). Droplets of suspensions are deposited on lacey carbon films (e.g. NetMesh $^{\mathrm{TM}}$ from Pelco) supported by TEM copper grids, or on perforated support foils with predefined arrangements of calibrated holes (e.g. C-flat ${ }^{\mathrm{TM}}$ from Protochips or Quantifoil ${ }^{\mathrm{TM}}$ from Quantifoil Micro Tools) that are particularly useful for automated image recording. The liquid in excess is blotted off with filter paper and the thin remaining film standing in the holes is quench-frozen in liquid ethane (Harris 1997). The frozen specimen is transferred into a cryo-specimen holder precooled with liquid nitrogen, then into the microscope, and observed at low temperature (around $-180^{\circ} \mathrm{C}$ ). Commercial workstations equipped with a temperature / humidity-controlled chamber and automated plungers (Vitrobot ${ }^{\mathrm{TM}}$ from FEI, $\mathrm{EM} \mathrm{GP}^{\mathrm{TM}}$ from Leica or Cryoplunge ${ }^{\mathrm{TM}}$ from Gatan) aim at improving the reproducibility of the cryofixation procedure. Cryo-TEM is not limited to aqueous suspensions but care must be taken when organic solvents are used since many of them are soluble in liquid ethane or crystallize when frozen in liquid nitrogen (Schappacher et al. 2005). 
Cryo-TEM has been used to visualize aqueous suspensions of non-flocculating cotton CNCs prepared by sulfuric acid hydrolysis, revealing the electrostatic repulsion due to surface charges on the particles (Figure 2a) (Elazzouzi-Hafraoui et al. 2008; Abitbol et al. 2013), as well as the interaction of CNCs with liposomes in different $\mathrm{pH}$ conditions (Navon et al. 2017). Figures 2b and 2c show Glaucocystis and cotton CNCs dispersed in films of vitreous ice and toluene, respectively. Chemically modified $\mathrm{CNCs}$ have also been observed to characterize the tunable aggregation of thermo-responsive polymer-grafted CNCs (Azzam et al. 2016) and the site-specific surface modification of CNCs, resulting in patchy nanoparticles (Zoppe et al. 2017). Combined with a tomography analysis (see the section dedicated to electron tomography in this article), cryo-TEM allows visualizing the $3 \mathrm{D}$ conformation of dendronized-polymer-wrapped CNCs (Majoinen et al. 2014) and the distribution of gold nanoparticles synthesized on CNCs used as chiral templates (Majoinen et al. 2016).
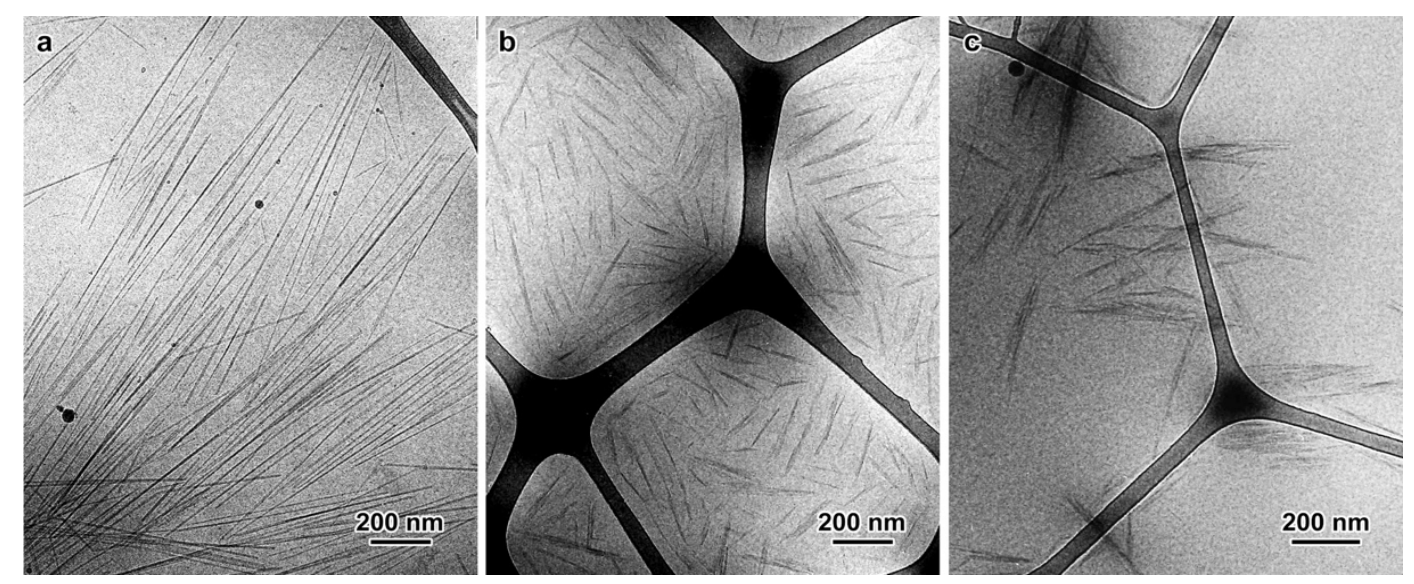

Figure 2. Cryo-TEM images of Glaucocystis (a) and cotton CNCs embedded in vitreous ice (b) and toluene (c). The lacy carbon framework is dark $(80 \mathrm{kV}$, images recorded on films. Images $b$ and $c$ courtesy of Elazzouzi-Hafraoui, CERMAV).

\subsection{Ultramicrotomy}

This preparation technique should be used for bulk materials like plant tissues, cell wall fragments, nanocomposites, and fibers. If necessary, in order to preserve the ultrastructure, the samples are first fixed with buffered fixatives, such as paraformaldehyde / glutaraldehyde in sodium cacodylate buffer solution. Then, the samples are generally embedded in a hardening resin (e.g. Epon ${ }^{\mathrm{TM}}$, LR White ${ }^{\mathrm{TM}}$, Durcupan ${ }^{\mathrm{TM}}$ or Quetol ${ }^{\mathrm{TM}}$ ) prior to sectioning (Glauert 1975). Ultrathin (50-100 nm) sections are cut at room temperature with an ultramicrotome equipped with a diamond knife (Reid 1975). The sections floating on water are collected on bare or carbon-coated copper grids. To enhance the contrast and selectively 
reveal specific regions of the specimen, the sections may be post-stained with stains such as uranyl acetate / Reynolds lead citrate (Harris 1997). If the sample is soft at room temperature, it can be hardened by cooling it down typically to $100 \mathrm{~K}$. It is then sectioned under cryogenic conditions with a dedicated cryo-ultramicrotome. Various images of stained or unstained sections of cellulose-containing organisms or wood can be found in the literature (for instance, Valonia cell walls (Revol 1982), tunicate glomerulocytes (Kimura and Itoh 1995), whereas images of cryosections of nanocomposites incorporating CNCs as reinforcing fillers were published, for instance, by Favier et al. (1995) and Fumagalli et al. (2017).

\section{Observation techniques}

Assuming that the sample preparation has been optimized, satisfactory TEM images of nanocellulose should exhibit a good signal-to-noise ratio and show fine details of the objects. The various contrasts observed in the images are generated by the physical interaction of the incident beam of electrons with the specimen (Watt 1997) and these images with their sometimes weak contrast must be properly recorded by a sensitive "detector".

\subsection{Recording devices}

For many years, TEM micrographs were exclusively recorded on electron-sensitive films which involved chemical developing and fixing treatments. Images were finally printed on paper in a dark room or, later on, the negatives were digitized off-line with a scanner. For several years, the so-called imaging plate has been an alternative detecting device, Fujifilm being the main manufacturer. These electron-sensitive plates exhibited higher dynamics and better linearity compared to films. They were read off-line with a specific reader that scanned a laser beam on the plate surface. This allowed retrieving digital images and electron diffraction patterns that could be used for quantitative intensity analysis. Another advantage was that the plates were re-usable many times after being "erased" using a strong illumination by visible light.

These approaches have been progressively replaced by direct digital image recording. Nowadays, most microscopes are equipped with cameras featuring $1 \mathrm{k} \times 1 \mathrm{k}$ to $4 \mathrm{k} \times 4 \mathrm{k}$ pixellarge CCD (charge-coupled device) or CMOS (complementary metal-oxide semiconductor) detectors. With high dynamics and good linearity, these cameras are very sensitive, which allows recording images with a variable frame rate, short exposure times and low electron doses. Electron diffraction patterns can also be recorded with digital cameras, with shorter exposure times and at higher camera lengths compared to those used for photographic films. However, great care must be taken to prevent any permanent damage of the detector by the 
highly intense transmitted beam (use of a beam stop, lower doses or short exposure times). In addition, the software that drives the camera can process the signal in real time, allowing, for instance, on-line motion and aberration correction, or calculation of the fast-Fourier transform. More recently, single-electron counting direct detection cameras have particularly been developed for low-dose applications and cryo-TEM, with significantly higher frame rate and sensitivity (Li et al. 2013).

\subsection{Different types of contrasts}

The overall contrast of nanocelluloses in a TEM image generally contains three main contributions. Since polymer particles are mostly composed of light elements, which weakly scatter electrons, the so-called amplitude contrast is generally weak. The amount of transmitted and scattered electrons depends on the density and thickness of the specimen. To create a contrast in the image, the operator inserts an objective aperture in the back focal plane of the objective lens. If this aperture is centered with respect to the incident beam, depending on its diameter, a fraction of scattered electrons is stopped and an image of the transmitted (or weakly scattered) electrons is formed. In this so-called bright-field image, if the objective lens is underfocused, the dark regions should thus be those that scattered the most electrons. In the dark-field mode, the aperture is centered on one or several diffraction spots and the bright areas in the image correspond to the sample regions that are in the corresponding Bragg conditions.

Diffraction contrast occurs when the specimen is crystalline or semicrystalline. It does not depend on the chemical composition but rather on the orientation of the crystalline domains with respect to the incident beam. For a discrete set of orientation angles defined by the unit cell of the crystal and determined using Bragg's relation, the electrons will be diffracted away from the optical axis (Watt 1997). In the so-called bright-field mode and with a negative defocus, when the diffracted electrons are stopped by the objective lens aperture, the regions of the particle from which the diffracted beams originate are significantly darker compared to the non-diffracting regions and the clear background from the amorphous supporting carbon film. This effect is important when visualizing semicrystalline nanocelluloses as it somewhat compensates for the low amplitude contrast. It is stronger for cellulose with a larger crystallite size, such as that of Valonia or tunicates (Bourret et al. 1972; Revol 1982). However, one can only take advantage of the diffraction contrast for a limited time since cellulose is highly sensitive to beam damage and is rapidly decrystallized under irradiation. Diffraction and diffraction contrast imaging are discussed in more detail in a further section of this article. 

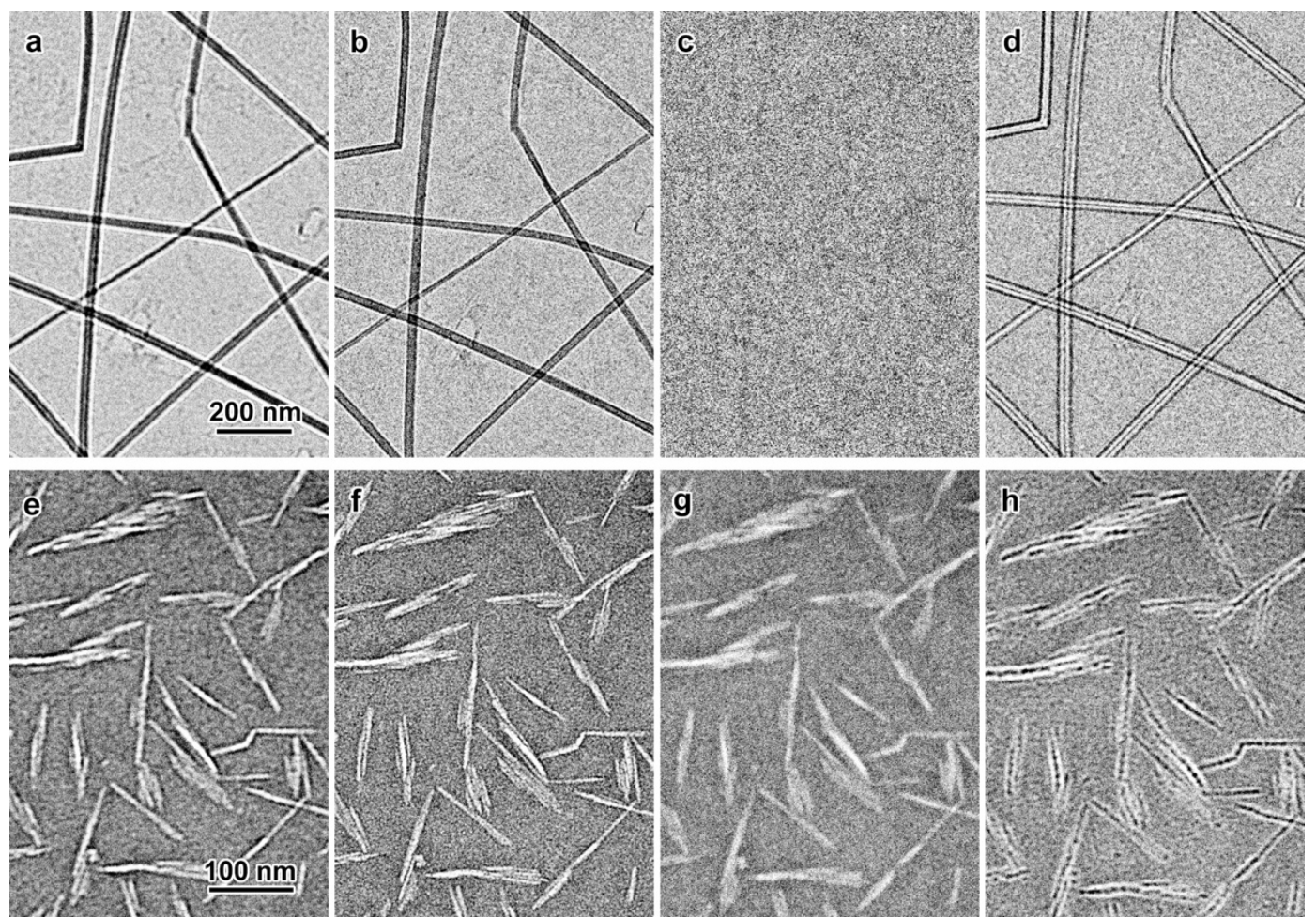

Figure 3. Effect of objective lens defocus on the contrast of unstained Valonia cellulose microfibrils (a-d) and negatively stained wood nanocrystals (e-h) (images recorded at $200 \mathrm{kV}$ with a digital camera). For images $a, b$, e and $f$, the objective lens is underfocused while it is at zero defocus in $\mathrm{c}$ and $\mathrm{g}$ and overfocused in $\mathrm{d}$ and $\mathrm{h}$. The defocus would be considered as optimal (slightly underfocused) for images $b$ and $f$.

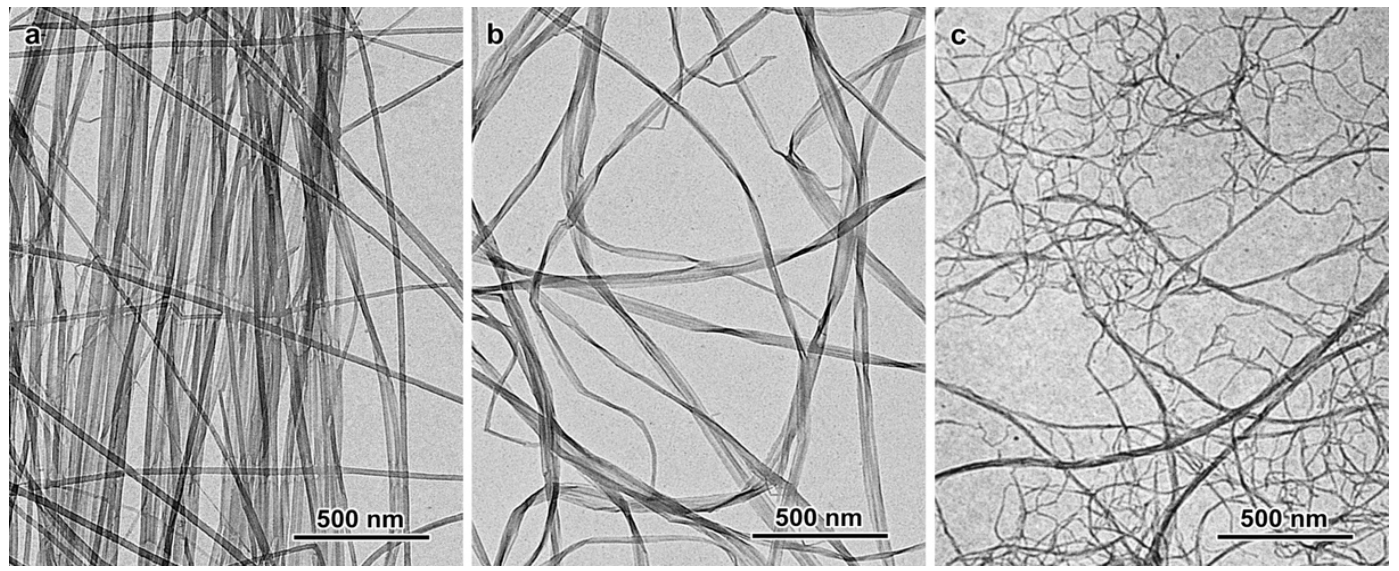

Figure 4. Low-dose bright-field images of unstained cellulose microfibrils from Valonia (a), Gluconacetobacter xylinus (b), and sugar beet parenchyma (c). The images were recorded at $80 \mathrm{kV}$ with a digital camera $(\mathrm{a}, \mathrm{b})$ and on film (c).

Phase contrast, or Fresnel contrast, is crucial in the case of particles that are transparent to electrons. It results from sharp differences in scattering properties between regions of the specimen, in particular when surfaces and interfaces are involved. The effect can be observed, for instance, for unstained CNFs or CNCs spread on a carbon film (particles in vacuum), and 
CNC suspensions observed by cryo-TEM (particles embedded in vitreous ice). Phase contrast generates interference Fresnel fringes whose amplitude and distribution depend on the defocus of the objective lens (Watt 1997). The effect of phase contrast on the image of unstained Valonia CNFs is illustrated in Figure 3a-d). High positive or negative defocus values increase the contrast but also generate larger Fresnel fringes and increase the apparent size of the nanoparticles, up to the point when the objects look blurry. Note the complete reverse of contrast between underfocused and overfocused images. In overfocused images, the $\mathrm{CNCs}$ are clear with a dark outline. Around zero defocus, the contrast is minimal and the specimen becomes nearly invisible. Therefore, in order to get a satisfactory image, the operator must balance the opposing requirements of contrast and ultrastructural detail, and set the defocus so that the contrast is higher, with the Fresnel fringes around the particles creating an impression of sharp edges. By convention, the images should be recorded in underfocused conditions, the amount of applied defocus increasing with decreasing magnification (typically, about $-5 \mu \mathrm{m}$ at $3000 \times$ and $-1 \mu \mathrm{m}$ at $10000 \times$ ). The effect of defocus on the image of negatively stained wood CNCs is also illustrated in Figure 3e-h.

The three types of contrast contribute to the image of unstained nanocellulose (Figure 4). A weak amplitude contrast occurs due to the small size and organic nature of the particles while the crystalline nature of the particles may generate a significant diffraction contrast in specific regions depending on the particle orientation with respect to the incident beam. Finally, the presence of Fresnel fringes around the objects can be controlled by the amount of defocus. However, as explained in the following section, all these contrasts are affected by radiation damage.

\subsection{Radiation damage}

Even if the theoretical point resolution of selected microscope allows visualizing details down to about $0.1-0.2 \mathrm{~nm}$, the sample itself and its interaction with the incident electron beam impose drastic constraints during the observation. The significant damage created by the electrons crossing a low-density polymer specimen rapidly affects the resolution of smaller details and decreases the contrast of the objects. Molecular excitations and ionization phenomena are induced in the material by the inelastic scattering of the electrons, resulting in the breaking of covalent bonds, diffusion of created free radicals and emission of volatile species (Dobb and Murray 1974; Grubb 1974). The consequences can be mass loss, melting, vaporization and crystallinity decrease, which have a detrimental impact on the amplitude, diffraction and Fresnel contrasts. By monitoring the disappearance of electron diffraction 
reflections of a crystalline material, a critical dose can be evaluated at which the crystal organization is irreversibly lost. This has been made easier in the recent years since digital cameras can precisely measure the incident electron dose during image recording.

The detrimental effects of beam damage can be partly controlled. First, increasing the accelerating voltage of the electrons (i.e. their energy) decreases the interactions with the polymer and thus increases the critical dose. Typically, increasing the voltage from 100 to $200 \mathrm{kV}$ increases the critical dose by a factor of 2 . The weaker interaction at a higher voltage also implies that the contrast is lower, which can be problematic with thin specimens of light polymer materials. Chanzy (1975) has submitted Valonia CNFs to increasing electron doses at various accelerating voltages, at room temperature, and monitored the intensity decrease of selected reflections in the electron diffraction pattern. He has evaluated an average lethal dose of $4 \mathrm{e}^{-} \AA^{-2}$ at $320 \mathrm{kV}$ for which the diffraction spot intensities were decreased by half. Sugiyama et al. (1985) determined a similar value for Valonia cellulose at $200 \mathrm{kV}$ but measured a critical dose of about $0.6 \mathrm{e}^{-} \AA^{-2}$ for wood cellulose (Sugiyama et al. 1986). These values attest to the extreme sensitivity of cellulose toward electron beams.

Therefore, in order to preserve the structure of the specimen as long as possible, the operator must work with electron doses much lower than the critical dose, by using low magnifications and significantly lower illumination intensity (e.g. by changing the "spot size" and spreading the illuminating beam). To observe unstained cellulose specimens, the operator must make a compromise between image magnification (to visualize high-resolution details) and electron dose (to have a sufficient signal-to-noise ratio for the camera recording).

The images in Figure 5 qualitatively illustrate the cumulative effect of beam damage on cellulose. In Figure 5a-d, wood CNCs have been submitted to increasing electron doses, at room temperature. The contribution of the three types of contrasts previously described are rapidly and irreversibly affected: diffraction contrast by disruption of the crystallinity, amplitude contrast by mass loss and phase contrast by thinning of the particle and surface damage, leading to CNCs with indistinct contours. Figure 5e illustrates the effect of a stronger beam on a mat of Valonia CNFs. The region that has been more intensively irradiated can be clearly seen at the center of the image where the contrast is lower and the damaged nanofibrils less defined.

In addition to increasing the accelerating voltage, the radiation damage can be significantly slowed down (but not suppressed) by keeping the specimen at low temperature during the observation, using a cryo-holder cooled down with liquid nitrogen (Dobb and Murray 1974). In that case, the critical dose is increased by a factor of about 3 (Wade 1984; Talmon 1987). 

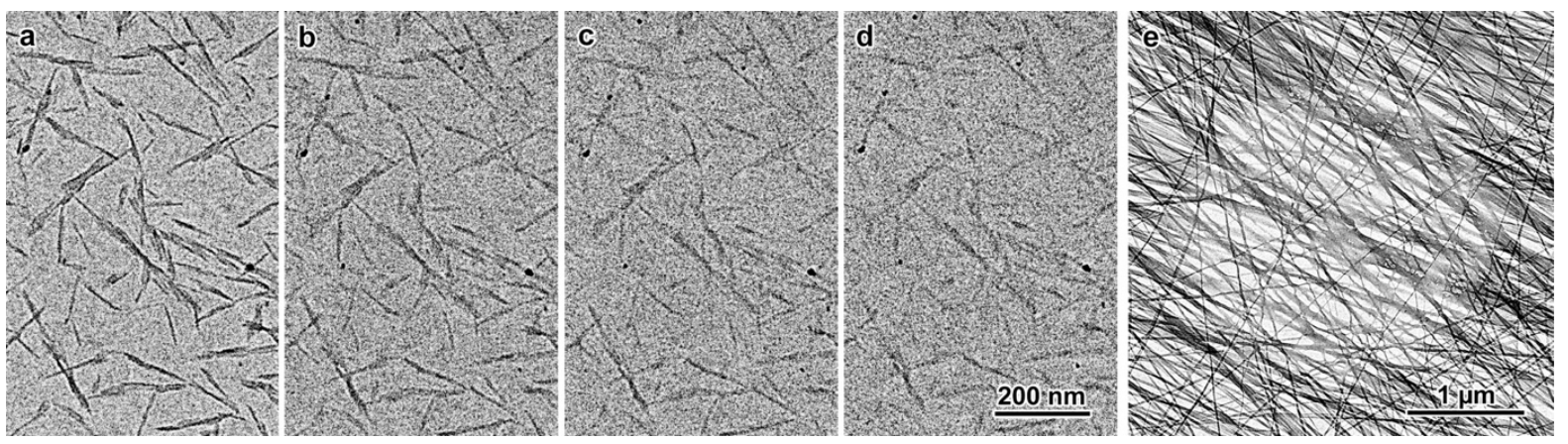

Figure 5. Impact of radiation damage on the contrast of unstained nanocellulose samples: a-d) wood CNCs with irradiation time increasing from a to d (images recorded at room temperature, at $200 \mathrm{kV}$, with a digital camera); e) Valonia CNFs. The clearer central disk corresponds to a region where the incident beam was briefly concentrated, resulting in a visible damage.

In order to assist the operator in the difficult task of recording images or radiation sensitive specimens, TEM manufacturers have implemented semi-automated procedures whereby the illumination parameters are controlled by the operating system (of the microscope or of the digital camera) in order to preserve the area of interest of the specimen before the image is actually recorded (for instance, the Minimum Dose System by Jeol and Low Dose System by Thermo Fisher Scientific-FEI-Philips). The procedure generally consists of three steps (Fujiyoshi et al. 1980): i) in search mode, the operator can select the region of interest at a low magnification and a low illumination dose; ii) in focus mode, the image defocus is set up at a higher magnification and a higher dose but at a distance of the region of interest so that it is not irradiated, then the beam is blanked; iii) in exposure mode, the beam is de-blanked and the image of the region of interest is recorded at the predetermined electron dose.

\subsection{Electron tomography}

Since TEM images are 2D projections of the 3D objects along the beam direction, information is lost along this direction. In order to make a reliable morphological analysis of the shape of particles, a series of 2D images must be recorded at different tilt angles of the specimen, which can be achieved in modern microscopes, thanks to the use of digital cameras and software that precisely control specimen orientation and image acquisition. The contrast in each $2 \mathrm{D}$ image is related to the mass-density distribution in the specimen. Images are automatically recorded with small tilt increments over a large angular range (typically -70 to $+70^{\circ}$ ). Using specific software, the collected images are aligned with respect to one another 
and back-projected to calculate a 3D reconstruction of the specimen volume (Fridman 2012; Frank 2008; Kremer 1996). While this technique is now widely used to study the morphology and structure of biological systems, including proteins, viruses and membranes (Fridman 2012; Dunstone and de Marco 2017), a few spectacular examples of 3D reconstruction of CNC-based systems observed by cryo-TEM can be found in the literature (Majoinen et al. 2014; Majoinen et al. 2016). As previously explained, unstained nanocellulose rapidly degrades due to radiation damage resulting in a loss of amplitude contrast during the recording of the tilt series. This recording requires extremely low beam intensity and a highly sensitive digital camera so that the specimen ultrastructure is preserved during the recording of the whole set of images. It has to be noted that electron tomography can also be performed on ultrathin sections of plant cell walls. For example, the technique has been used to study the geometry and distribution of CNFs into fragments of chemically and thermally treated biomass (Ciesielski et al. 2013; Hinkle et al. 2015) and spruce tracheids (Reza et al. 2014; Reza et al. 2017).

\section{Electron diffraction and diffraction contrast imaging}

\subsection{Electron diffraction (ED)}

ED allows investigation of crystallographic features locally from the nano- to the microscale in contrast to X-ray scattering that provides global structural information from powders, fibers or bulk macroscopic specimens. Depending on its orientation with respect to the incident beam and the wavelength of the electrons, a crystal lattice diffracts electrons according to a discrete set of angles defined by the unit cell and symmetry of the crystal using Bragg's relation. By changing the settings of the microscope, it is possible to visualize the pattern that is produced by the scattered electrons and formed in the back focal plane of the objective lens (Watt 1997).

The most common method is the so-called selected area electron diffraction (SAED). An aperture located below the sample on the path of the electrons is inserted to select a limited region of the specimen in the image (typically $200 \mathrm{~nm}$ to $1 \mu \mathrm{m}$ in diameter). Although the sample is still illuminated (and thus damaged) by the whole incident beam, only the electrons going through the SA aperture are used to form the diffraction pattern. Since all the crystallites in the selected area contribute to the resulting pattern, randomly oriented crystals yield an isotropic ring "powder" pattern, whereas a bundle of parallel particles generates an anisotropic "fiber" pattern containing arcs and a single crystal yields a spot pattern. The 
distribution and intensity of the reflections in the ED patterns can be used to unambiguously identify the crystal structure of a given sample and, after proper calibration and indexing, its unit cell parameters can be calculated.
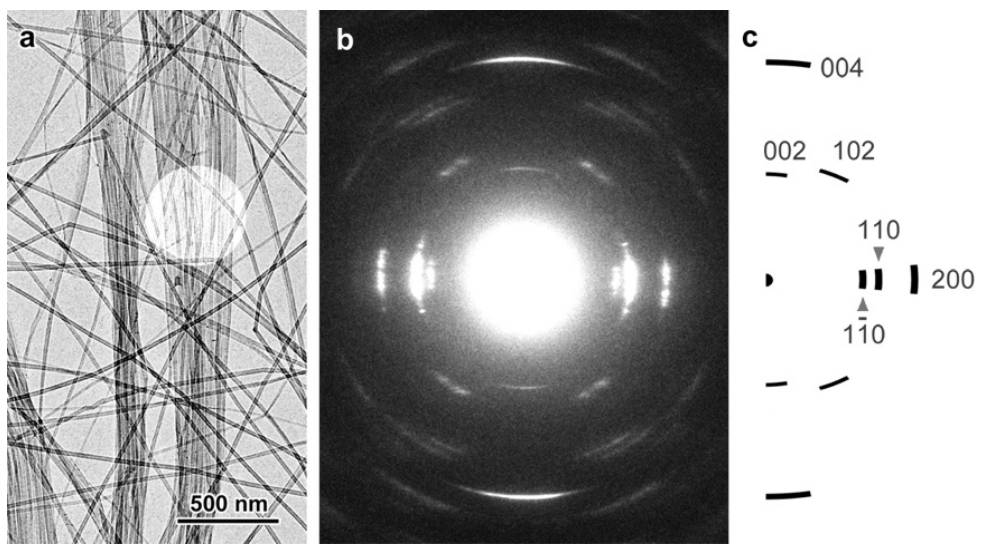

Figure 6. a) TEM image of Valonia cellulose microfibrils; b) SAED fiber pattern of a bundle of Valonia cellulose microfibrils recorded on the selected area indicated in (a) (low temperature, $200 \mathrm{kV}$, digital camera). The pattern is properly oriented with respect of the image; c) corresponding Miller indices of the main reflections (cellulose I $\beta$ ) as defined by Sugiyama et al. (1991).
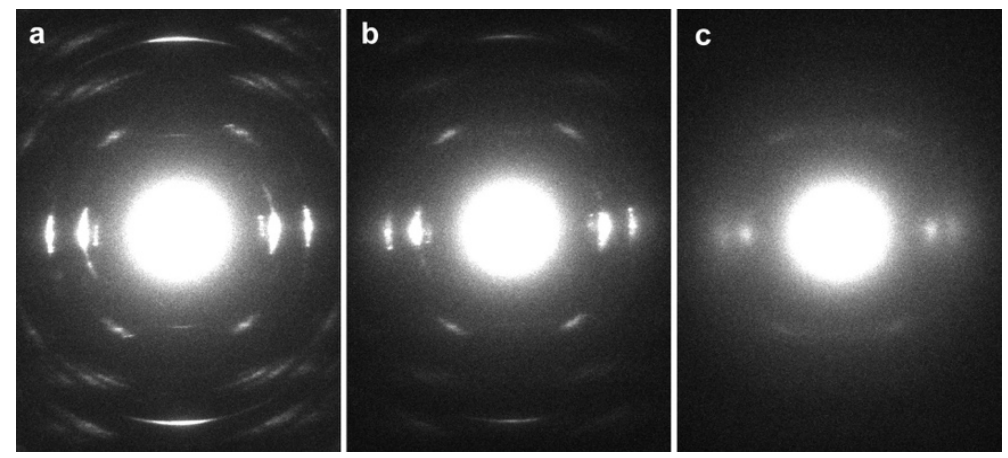

Figure 7. Impact of electron radiation damage on the electron diffraction fiber patterns from a bundle of Valonia cellulose microfibrils. The images were recorded at $200 \mathrm{kV}$, at low temperature, with a $2 \mathrm{~s}$ exposure time on a digital camera, with a $20 \mathrm{~s}$ irradiation between each of them.

Note that in some microscopes, the ED pattern can be rotated with respect to the image so this rotation must be calibrated in order to correctly align the pattern with the image. One method to do so is to select an object with a size smaller than that of the SA aperture, then defocus the ED pattern so that the image of the object gets visible inside the enlarged transmitted beam. In that case, the orientation of the object can be compared with that in image mode and the rotation can be measured. 
The first ED patterns of cellulose were recorded from Valonia cell walls by Preston and Ripley (1954). To limit the detrimental effect of radiation damage, Honjo and Watanabe (1958) decreased the temperature of the sample and recorded a higher resolution pattern. A typical ED fiber pattern recorded at low temperature from a bundle of Valonia CNFs is shown in Figure 6, as well as the corresponding indexing from native cellulose I $\beta$ (Sugiyama et al. 1991). In such a pattern, the sharp 004 meridional arc at a $d$-spacing of $0.26 \mathrm{~nm}$ is characteristic of crystalline cellulose, while the thin 002 meridional arc is characteristic of the I $\beta$ allomorph. The effect of extended irradiation on the intensity and width of the diffraction arcs, resulting in the disappearance of high-resolution information, is shown in Figure 7 (Dobb and Murray 1974). In addition, Revol (1985) has shown that upon irradiation, the position of the equatorial 200 reflection changed, corresponding to a continuous but slight increase of the $d$-spacing. SAED fiber patterns also permitted unambiguous identification of allomorphic variations in native (Nakashima et al. 2011) or chemically treated (Chanzy and Roche 1976; Chanzy et al. 1987; Faria-Tischer et al. 2015; Zuluaga et al. 2009) cellulose samples.

Microdiffraction is used to obtain more local structural information compared to that recorded by SAED. The size and intensity of the incident electron beam are decreased using a first condenser aperture with a diameter in the range of 10 to $20 \mu \mathrm{m}$ and the beam is focused to form an electron probe with a diameter smaller than $100 \mathrm{~nm}$. With this narrow electron beam, a single crystal ED spot pattern can be recorded from a small region along a CNF or a CNC. While certainly more difficult to master, the microdiffraction technique has played a significant role in identifying the I $\alpha$ and I $\beta$ allomorphs in native cellulose (Sugiyama et al. 1991) and their localization (Imai and Sugiyama 1998; Horikawa and Sugiyama 2009) by providing unambiguous information on crystal unit cell and symmetry. Performing electron microdiffraction on sensitive specimens is very challenging since this technique involves focused electron beams that may cause fast and extensive local damage on the crystal. To minimize this effect, the operation has to be carried out under a very low dose condition, and preferably at low temperature.

\subsection{Diffraction contrast imaging}

Diffraction contrast imaging is a potent technique to visualize the morphology and size of crystalline domains as a strong diffraction contrast originates only from the crystalline regions of unstained specimens. As previously explained, an aperture with a sufficiently small diameter (typically about $20 \mu \mathrm{m}$ ) is inserted in the back focal plane of the objective lens. 
By visualizing the SAED pattern, the operator can control the position of the aperture. In bright-field mode, the aperture is placed around the central transmitted beam, thus occulting the scattered electrons and, in the resulting image, the scattering / diffracting regions are dark (Figure 8a). If the aperture is translated to select one diffracted beam in the ED pattern, all other electrons are stopped and, in particular, those in the transmitted beam (Figure 8b). In this so-called dark-field image, the background is dark and the regions corresponding to the selected diffracted beam are white. Different diffracted beams can be selected in the ED pattern, thus modifying the illuminated regions in the image. The observation must be carried out under low-dose conditions since electron irradiation rapidly affects diffraction contrast and degrades fine details of cellulose crystals.
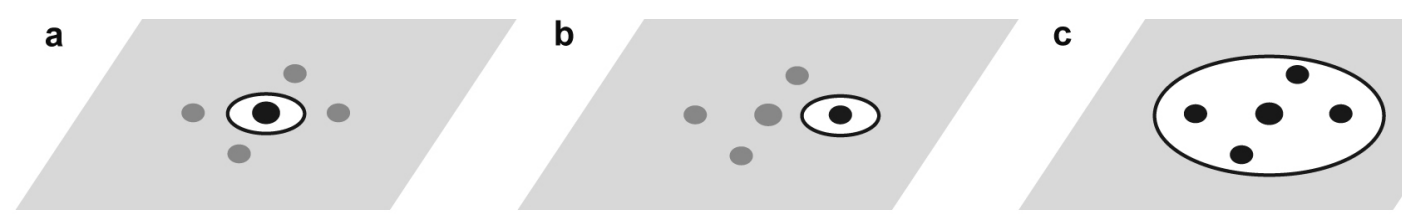

OL back focal plane
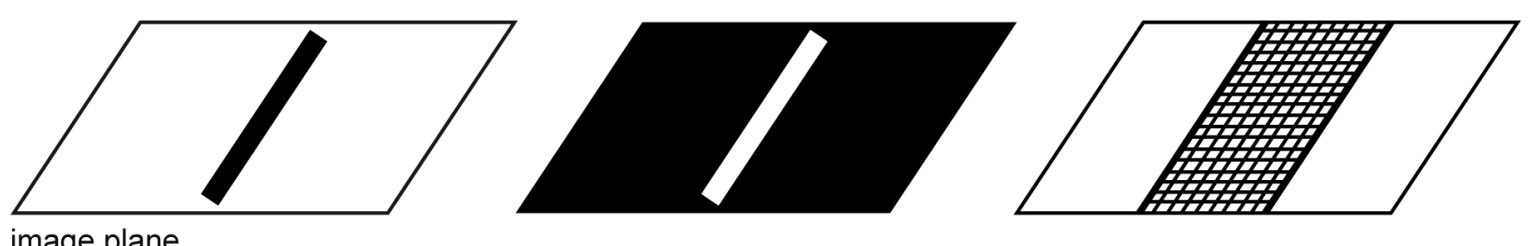

Figure 8. Schemes showing the size and position of the aperture that selects specific diffraction spots in the back focal plane of the objective lens (OL), and corresponding images of a crystalline rod in diffracting Bragg orientation, in bright-field (a) and dark-field (b) modes. The image in (c), recorded at higher magnification, shows fringes corresponding to a projection of the crystal lattice.

Bourret et al. (1972) produced the first dark-field images of Valonia CNFs, measuring the dimensions of the crystallites (Figure 9a), while bright-field images have brought important information on the cross-sectional morphology of microfibrils in several plant /alga cell wall specimens prepared by ultramicrotomy (Figures 9b and 9c) (Helbert et al. 1998; Kim et al. 1996; Näslund et al. 1988; Revol 1983; Sugiyama et al. 1985). Since the diffraction contrast depends on the orientation of lattice planes with respect to the incident electron beam and is strong only when the Bragg condition is satisfied, a small deviation of the fiber axis of crystal from the incident electron beam direction drastically decreases the image contrast (Roche and Chanzy 1981; Revol 1983). Thus, special care has to be taken for the orientation of cellulose crystals in ultrathin sections. Such an effect can be seen in Figure 9c where only 
the cross-sections perfectly perpendicular to the observation axis (i.e. the chain axis of cellulose is parallel to the incident beam) appear as dark polygons while tilted crystallites exhibit low-contrast blurry elongated shapes.
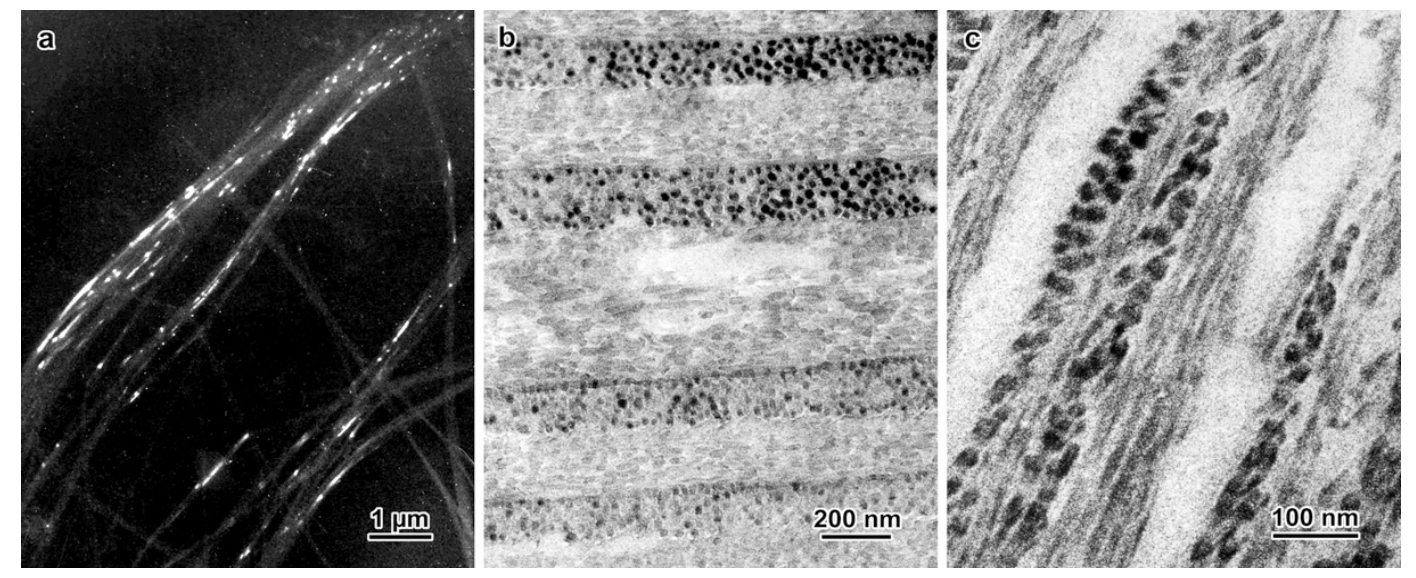

Figure 9. a) Dark-field TEM image of Valonia CNFs formed by selecting the 200 spot in the diffraction pattern. The Miller indices are defined according to the I $\beta$ unit cell described by Sugiyama et al. (1991). The bright areas correspond to regions of the fibrils with their $(200)$ crystallographic planes in Bragg orientation with respect to the electron beam (courtesy of H. Chanzy, CERMAV). b,c) Bright-field images of ultrathin sections of the cell walls of Cladophora (b) and Microdictyon (c) algae. Both walls exhibit a plywood-like organization of CNFs, each layer being rotated with respect to the neighboring ones. The sections are unstained and the contrast mostly arises from Bragg diffraction of cellulose crystallites. The well-defined dark squarish spots correspond to the cross-sections of the CNFs perpendicular to the fiber axis (courtesy of J. Sugiyama, RISH, and H. Chanzy, CERMAV). All images were recorded on films.

\subsection{High-resolution lattice imaging}

As was mentioned in Part 1 of this article (Ogawa et al. 2019), imaging cellulose at the molecular scale was a significant milestone in cellulose science (Sugiyama et al. 1985; Revol 1985; Kuga and Brown 1987). However, while the visualization of projections of the crystal lattice brought important information on the molecular organization, the technique is still highly challenging. Practically, a larger aperture is inserted in the back focal plane of the objective lens to select several diffraction spots symmetrically distributed around the transmitted beam (Figure 8c). The resulting interference pattern between the central and diffracted beams produces lattice images, with $d$-spacings associated to the selected reflections.

A sufficiently high magnification and therefore substantial electron doses are thus required. Since the dose must be decreased in order to preserve the crystal lattice, the image is generally highly underexposed and has a very low signal-to-noise ratio. Image processing routines are then used to enhance the signal and retrieve meaningful structural information. 
The previously described automated low-dose procedures are extremely helpful (if not mandatory) to successfully record lattice images without damaging the specimen before actual image recording. Cryo-specimen holders operated either at liquid nitrogen or liquid helium temperature can also be used to efficiently reduce the detrimental effect of beam damage (Helbert et al. 1998). Surprisingly, while such lattice images of nanocellulose (in longitudinal or cross-sectional view) have been successfully recorded on films (Sugiyama et al. 1985; Revol 1985; Kuga and Brown 1987; Imai et al. 2003), to our knowledge, a convincing image recorded with a digital camera is yet to be produced.

\section{Perspectives}

The development of highly sensitive and high-resolution digital cameras has brought exciting new opportunities for TEM imaging, not only in biological science, e.g. in protein structure determination, but also in materials science. This should also be the case for cellulose since these advanced detecting devices permit drastic reduction of the electron radiation dose to record meaningful images with a high signal-to-noise ratio.

With such high-resolution cameras, one may envisage the recording of lattice images, not only of the highly crystalline specimens, as it is done today, but also of the more common celluloses that are important in day-to-day life. In these celluloses, imaging elements like crystalline defects, chain ends, and amorphous domains should be of primary importance. Highly sensitive detection should also help the recording of advanced electron microdiffraction data that should provide definitive answers to remaining key problems about cellulose crystal structure, including the experimental quantification of crystal twist along the fiber axis, and the localization of the two allomorphs in native cellulose crystals.

Another long-lasting important question for cellulose crystals is to define the exact morphology of cellulose microfibrils in higher plants. This has been an especially challenging problem for electron microscopy since the crystallite size of the corresponding cellulose is much smaller, typically a few nm in diameter, than those of model cellulose crystals, and the critical dose under electron irradiation was shown to be much lower than that of larger algal cellulose nanofibrils (Sugiyama et al. 1986). Diffraction contrast under cryo conditions would seem to be the first approach to test. This question could also be addressed by high-resolution electron tomography of plant tissues since improving the signal-to-noise ratio of such images has been one of the main issues impeding visualization of such small electron-sensitive objects. A clear definition of the cross-sectional shape of individual cellulose microfibrils in 
higher plants will be crucial to confirm or refute the various cross-section models described in the literature. In particular, localization and imaging of the hydrophilic and hydrophobic surfaces of the cellulose microfibrils by combining diffraction contrast images and microdiffraction analyses would be a major advance. Identifying the polarity of individual microfibrils within any plant cell wall is also a goal that could be achieved with these advances in recording devices.

\section{Acknowledgements}

Most TEM images and diffraction diagrams displayed in this article have specifically been recorded for this paper using a FEI-Philips CM200 'Cryo' microscope operating at 80 or $200 \mathrm{kV}$. Most images have been recorded with a TVIPS TemCam F216 digital 2K camera. The authors would like to thank the NanoBio-ICMG Platform (FR 2607) for granting access to the Electron Microscopy facility, as well as the colleagues who have prepared the nanocellulose specimens that have been observed. We are extremely grateful to Henri Chanzy for sharing with us his vast knowledge of transmission electron microscopy of polysaccharides and for critically reading, and thus improving, this manuscript.

\section{References}

Abitbol T, Kloser E, Gray DG (2013) Estimation of the surface sulfur content of cellulose nanocrystals prepared by sulfuric acid hydrolysis. Cellulose 20:785-794. https://doi.org/10.1007/s10570-013-9871-0

Aebi U, Pollard TD (1987) A glow discharge unit to render electron microscope grids and other surfaces hydrophilic. J Electron Microsc Tech 7:29-33. https://doi.org/10.1002/jemt.1060070104

Azzam F, Siqueira E, Fort S, Hassaini R, Pignon F, Travelet C, Putaux J-L, Jean B (2016) Tunable aggregation and gelation of thermoresponsive suspensions of polymer-grafted cellulose nanocrystals. Biomacromolecules 17:2112-2119. https://doi.org/10.1021/acs.biomac.6b00344

Bourret A, Chanzy H, Lazaro R (1972) Crystallite features of Valonia cellulose by electron diffraction and dark field microscopy. Biopolymers 11:893-898. https://doi.org/10.1002/bip.1972.360110412

Brinkmann A, Chen M, Couillard M, Jakubek ZJ, Leng T, Johnston LJ (2016) Correlating cellulose nanocrystal particle size and surface area. Langmuir 32:6105-6114. https://doi.org/10.1021/acs.langmuir.6b01376

Brito BSL, Pereira FV, Putaux J-L, Jean B (2012) Morphology and structure of cellulose nanocrystals prepared from bamboo fibers. Cellulose 19:1527-1536. https://doi.org/10.1007/s10570-012-9738-9

Brown RM Jr (1996) The biosynthesis of cellulose. J Macromol Sci A 33:1345-1373. https://doi.org/10.1080/10601329608014912 
Chanzy HD (1975) Irradiation de la cellulose de Valonia au microscope à 1 MV. Bulletin BIST, CEA 207:55-57.

Chanzy HD, Roche EJ (1976) Fibrous transformation of Valonia cellulose I into cellulose II. Appl Polym Symp 28:701-711.

Chanzy H, Henrissat B, Vincendon M, Tanner SF, Belton PS (1987) Solid-state ${ }^{13}$ C-N.M.R. and electron microscopy study on the reversible cellulose I $\rightarrow$ cellulose III transformation in Valonia. Carbohydr Res 160:1-11. https://doi.org/10.1016/0008-6215(87)80299-9

Chauve G., Fraschini C., Jean B. (2014) Separation of cellulose nanocrystals. In "Handbook of Green Materials : Processing Technologies, Properties and Applications", Oksman K, Mathew AP, Bismark A, Rojas O, Sain M eds, World Sci Pub Co, vol 1, pp 73-87. https://doi.org/10.1142/9789814566469_0006

Chinga-Carrasco G (2011) Cellulose fibres, nanofibrils and microfibrils: The morphological sequence of MFC components from a plant physiology and fibre technology point of view. Nanoscale Res Lett 6:417. https://doi.org/10.1186/1556-276X-6-417

Ciesielski PN, Matthews JF, Tucker MP, Beckham GT, Crowley MF, Himmel ME, Donohoe BS (2013) 3D electron tomography of pretreated biomass informs atomic modeling of cellulose microfibrils. ACS Nano 7:8011-8019. https://doi.org/10.1021/nn4031542

Dobb MG, Murray R (1974) Towards higher resolution in electron beam sensitive specimens of biological origin. J Microsc 101:299-309. https://doi.org/10.1111/j.1365-2818.1974.tb03955.x

Dubochet J, Adrian M, Chang JJ, Homo JC, Lepault J, McDowall AW, Schultz P (1988) Cryo-electron microscopy of vitrified specimens. Q Rev Biophys 21:129-228. https://doi.org/10.1007/978-3-642-72815-0_5

Dubochet J, Ducommun M, Zollinger M, Kellenberger E (1971) A new preparation method for dark-field electron microscopy of biomacromolecules. J Ultrastruct Res 35:147-167. https://doi.org/10.1016/S0022-5320(71)80148-X

Dufresne A (2013) Nanocellulose: a new ageless material. Mater Today 16:220-227. http://dx.doi.org/10.1016/j.mattod.2013.06.004

Dunstone MA, de Marco A (2017) Cryo-electron tomography: an ideal method to study membrane-associated proteins. Phil Trans R Soc B 372:20160210. http://dx.doi.org/10.1098/rstb.2016.0210

Eichhorn SJ (2011) Cellulose nanowhiskers: promising materials for advanced applications. Soft Matter 7:303-315. https://doi.org/10.1039/c0sm00142b

Elazzouzi-Hafraoui S, Nishiyama Y, Putaux J-L, Heux L, Dubreuil F, Rochas C (2008) The shape and size distribution of crystalline nanoparticles prepared by acid hydrolysis of native cellulose. Biomacromolecules 9:57-65. https://doi.org/10.1021/bm700769p

Faria-Tischer PCS, Tischer CA, Heux L, Le Denmat S, Picart C, Sierakowski M-R, Putaux J-L (2015) Preparation of cellulose II and III films by allomorphic conversion of bacterial cellulose I pellicles. Mater Sci Eng C 51:167-173. https://doi.org/10.1016/j.msec.2015.02.025

Favier V, Chanzy H, Cavaillé J-Y (1995) Polymer nanocomposites reinforced by cellulose whiskers. Macromolecules 28: 6365-6367. https://doi.org/10.1021/ma00122a053

Flauzino Neto WP, Putaux J-L, Mariano M, Ogawa Y, Otaguro H, Pasquini D, Dufresne A (2016) Comprehensive morphological and structural investigation of cellulose I and II nanocrystals prepared by sulphuric acid hydrolysis. RSC Adv 6:76017-76027. https://doi.org/10.1039/c6ra16295a 
Foster JEJ, Moon RJ, Agarwal UP, Bortner MJ., Bras J., Camarero-Espinosa S, Chan KJ., Clift MJD, Cranston ED, Eichhorn SJ, Fox DM, Hamad WY, Heux L, Jean B, Korey M, Nieh W, Ong KJ, Reid MS, Renneckar S, Roberts R, Shatkin JA, Simonsen J, StinsonBagby K, Wanasekaraq N, Youngblood J (2018) Current characterization methods for cellulose nanomaterials. Chem Soc Rev 47:2609-2679. https://doi.org/10.1039/c6cs00895j

Frank J (2008) "Electron Tomography: Methods for Three-Dimensional Visualization of Structures in the Cell", Springer Science \& Business Media.

Fridman K, Mader A, Zwerger M, Elia N, Medalia O (2012) Advances in tomography: probing the molecular architecture of cells. Nat Rev Mol Cell Biol 13:736-742. https://doi.org/10.1038/nrm3453

Fujiyoshi Y, Kobayashi T, Ishizuka K, Uyeda N, Ishida Y, Harada Y (1980) A new method for optimal-resolution electron microscopy of radiation-sensitive specimens. Ultramicroscopy 5:459-468. https://doi.org/10.1016/S0304-3991(80)80004-0

Fumagalli M, Berriot J, de Gaudemaris B, Veyland A, Putaux J-L, Molina-Boisseau S, Heux L (2018) Rubber materials from elastomers and nanocellulose powders: Filler dispersion and mechanical reinforcement. Soft Matter 14:2638-2648. https://doi.org/10.1039/C8SM00210J

Glauert AM (1975) "Fixation, Dehydration and Embedding of Biological Specimens", NorthHolland/American, Elsevier.

Grubb D (1974) Radiation damage and electron microscopy of organic polymers. J Mater Sci 9:1715-1736. https://doi.org/10.1007/BF00540772

Habibi Y, Lucia LA, Rojas O (2010) Cellulose nanocrystals: Chemistry, self-assembly, and applications. Chem Rev 110:3479-3500. https://doi.org/10.1021/cr900339w

Harris JR (1997) "Negative Staining and Cryoelectron Microscopy: The Thin Film Techniques", RMS Microscopy Handbook, Oxford, BIOS Scientific Publishers.

Helbert W, Nishiyama Y, Okano T, Sugiyama J (1998) Molecular imaging of Halocynthia papillosa cellulose. J Struct Biol 124:42-50. https://doi.org/10.1006/jsbi.1998.4045

Helbert W, Sugiyama J, Kimura S, Itoh T (1998) High-resolution electron microscopy on ultrathin sections of cellulose microfibrils generated by glomerulocytes in Polyzoa vesiculiphora. Protoplasma 203:84-90. https://doi.org/10.1007/BF01280590

Hinkle JD, Ciesielski PN, Gruchalla K, Munch KR, Donohoe BS (2015) Biomass accessibility analysis using electron tomography. Biotechnol Biofuels 8:212. https://doi.org/10.1186/s13068-015-0395-8

Honjo G, Watanabe M (1958) Examination of cellulose fibre by the low-temperature specimen method of electron diffraction and electron microscopy. Nature 181:326-328. https://doi.org/10.1038/181326a0

Horikawa Y, Sugiyama J (2009) Localization of crystalline allomorphs in cellulose microfibril. Biomacromolecules 10:2235-2239. https://doi.org/10.1021/bm900413k

Imai T, Putaux J-L, Sugiyama J (2003) Geometric phase analysis of lattice images from algal cellulose. Polymer 44:1871-1879. https://doi.org/10.1016/S0032-3861(02)00861-3

Imai T, Sugiyama $J$ (1998) Nanodomains of $I_{\alpha}$ and $I_{\beta}$ cellulose in algal microfibrils. Macromolecules 31:6275-6279. https://doi.org/10.1021/ma980664h

Jakubek ZJ, Chen M, Couillard M, Leng T, Liu L, Zou S, Baxa U, Clogston JD, Hamad WY, Johnston LJ (2018) Characterization challenges for a cellulose nanocrystal reference material: dispersion and particle size distributions. J Nanopart Res 20:98. https://doi.org/10.1007/s11051-018-4194-6 
Kargarzadeh H, Mariano M, Gopakumar D, Ahmad I, Thomas S, Dufresne A., Huang J, Lin N (2018) Advances in cellulose nanomaterials. Cellulose 25:2151-2189. https://doi.org/10.1007/s10570-018-1723-5

Kaushik M, Chen WC, van de Ven TGM, Moores A (2014) An improved methodology for imaging cellulose nanocrystals by transmission electron microscopy. Nord Pulp Pap Res J 29:77-84. https://doi.org/10.3183/NPPRJ-2014-29-01-p077-084

Kaushik M, Fraschini C, Chauve G, Putaux J-L, Moores A (2015) Transmission electron microscopy for the characterization of cellulose nanocrystals. In "The Transmission Electron Microscope - Theory and Applications", K. Maaz ed., InTech, pp. 129-163. https://doi.org/10.5772/60985

Kim N-H, Herth W, Vuong R, Chanzy H (1996) The cellulose system in the cell wall of Micrasterias. J Struct Biol 117:195-203. https://doi.org/10.1006/jsbi.1996.0083

Kimura S, Itoh T (1995) Evidence for the role of the glomerulocyte in cellulose synthesis in the tunicate Metandrocarpa uedai. Protoplasma 186:24-33. https://doi.org/10.1007/BF01276931

Kimura S, Itoh T (2004) Cellulose synthesizing terminal complexes in the ascidians. Cellulose 11:377-383. https://doi.org/10.1023/B:CELL.0000046414.72903.33

Klemm D, Cranston E, Fischer D, Gama M, Kedzior SA, Kralisch D, Kramer F, Kondo T, Lindström T, Nietzsche S, Petzold-Welcke K, Rauchfuß F (2018) Nanocellulose as a natural source for groundbreaking applications in materials science: Today's state. Materials Today 21:720-748. https://doi.org/10.1016/j.mattod.2018.02.001

Klemm D, Heublein B, Fink H-P, Bohn A (2005) Cellulose: Fascinating biopolymer and sustainable raw material. Angew Chem Int Ed 44:3358-3393. https://doi.org/10.1002/anie.200460587

Kremer JR, Mastronarde DN, McIntosh JR (1996) Computer visualization of threedimensional image data using IMOD. J Struct Biol 116:71-76. https://doi.org/10.1006/jsbi.1996.0013

Kuga S, Brown RM Jr (1987) Practical aspects of lattice imaging of cellulose. J Electr Microsc Technique 6:349-356. https://doi.org/10.1002/jemt.1060060405

Lahiji RR, Xu X, Reifenberger R, Raman A, Rudie A, Moon RJ (2010) Atomic force microscopy characterization of cellulose nanocrystals. Langmuir 26:4480-4488. https://doi.org/10.1021/la903111j

Li X, Mooney P, Zheng S, Booth C, Braunfeld MB, Gubbens S, Agard DA, Cheng Y (2013) Electron counting and beam-induced motion correction enable near atomic resolution single particle cryoEM. Nat Methods 10:584-590. https://doi.org/10.1038/nmeth.2472

Lin N, Dufresne A (2014) Nanocellulose in biomedicine: Current status and future prospect. Europ Polym J 59:302-325. http://dx.doi.org/10.1016/j.eurpolymj.2014.07.025

Majoinen J, Haataja JS, Appelhans D, Lederer A, Olszewska A, Seitsonen J, Aseyev V, Kontturi E, Rosilo H, Österberg M, Houbenov N, Ikkala O (2014) Supracolloidal multivalent interactions and wrapping of dendronized glycopolymers on native cellulose nanocrystals. J Am Chem Soc 136: 866-869. https://dx.doi.org/10.1021/ja411401r

Majoinen J, Hassinen J, Haataja JS, Rekola HT, Kontturi E, Kostiainen MA, Ras RHA, Törmä P, Ikkala O (2016) Chiral plasmonics using twisting along cellulose nanocrystals as a template for gold nanoparticles. Adv Mater 28:5262-5267. https://doi.org/10.1002/adma.201600940

Manley RStJ (1971) Molecular morphology of cellulose. J Polym Sci A2 9:1025-1059. https://doi.org/10.1002/pol.1971.160090604 
Michen B, Geers C, Vanhecke D, Endes C, Rothen-Rutishauser B, Balog S, Petri-Fink A (2015) Avoiding drying-artifacts in transmission electron microscopy: Characterizing the size and colloidal state of nanoparticles. Sci Rep 5:9793. https://doi.org/10.1038/srep09793

Mukherjee SM, Woods HJ (1953) X-ray and electron microscope studies of the degradation of cellulose by sulphuric acid. Biochim Biophys Acta 10: 499-511. https://doi.org/10.1016/0006-3002(53)90295-9

Nakashima K, Nishino A, Horikawa Y, Hirose E, Sugiyama J, Satoh N (2011) The crystalline phase of cellulose changes under developmental control in a marine chordate. Cell Mol Life Sci 68:1623-1631. https://doi.org/10.1007/s00018-010-0556-7

Näslund P, Vuong R, Chanzy H, Jésior J-C (1988) Diffraction contrast transmission electron microscopy on flax fiber ultrathin cross sections. Text Res J 58:414-417. https://doi.org/10.1177/004051758805800707

Navon Y, Radavidson H, Putaux J-L, Jean B, Heux L (2017) pH-Sensitive interactions between cellulose nanocrystals and DOPC liposomes. Biomacromolecules 18:29182927. https://doi.org/10.1021/acs.biomac.7b00872

Nishiyama Y (2009) Structure and properties of the cellulose microfibril. J Wood Sci 55:241249. https://doi.org/10.1007/s10086-009-1029-1

Ogawa Y, Chanzy H, Putaux J-L (2019) Transmission electron microscopy of cellulose. Part 1: Historical perspective. Cellulose 26:5-15. https://doi.org/10.1007/s10570-018-2076-9

Oksman K, Aitomäki Y, Mathew AP, Siqueira G, Zhou Q, Butylina S, Tanpichai S, Zhou X, Hooshmand S (2016) Review of the recent developments in cellulose nanocomposite processing. Composites: Part A 83:2-18. http://dx.doi.org/10.1016/j.compositesa.2015.10.041

Preston R, Ripley G (1954) Electron diffraction diagrams of cellulose micro-fibrils in Valonia. Nature 174:76-77. https://doi.org/10.1038/174076a0

Preston RD (1971) Negative staining and cellulose microfibril size. J Microscopy 93:7-13. https://doi.org/10.1111/j.1365-2818.1971.tb02260.x

Rånby B (1952a) Physico-chemical investigations on animal cellulose (Tunicin). Arkiv för Kemi 4:241-248.

Rånby B (1952b) Physico-chemical investigations on bacterial cellulose. Arkiv för Kemi 4:249-255.

Reid M, Villalobos M, Cranston E (2017) Benchmarking cellulose nanocrystals: From the laboratory to industrial production. Langmuir 33:1583-1598. https://doi.org/10.1021/acs.langmuir.6b03765

Reid N (1975) Practical Methods in Electron Microscopy: Ultramicrotomy. NorthHolland/American: Elsevier.

Revol J-F (1982) On the cross-sectional shape of cellulose crystallites in Valonia ventricosa. Carbohydr Polym 2:123-134. https://doi.org/10.1016/0144-8617(82)90058-3

Revol J-F (1985) Change of the $d$-spacing in cellulose crystals during lattice imaging. J Mater Sci Lett 4:1347-1349. https://doi.org/10.1007/BF00720097

Revol J-F, Goring DAI (1983) Directionality of the fibre $c$-axis of cellulose crystallites in microfibrils of Valonia ventricosa. Polymer 24:1547-1550. https://doi.org/10.1016/0032-3861(83)90168-4

Reza M, Bertinetto C, Ruokolainen J, Vuorinen T (2017) Cellulose elementary fibrils assemble into helical bundles in S1 layer of spruce tracheid wall. Biomacromolecules 18:374-378. https://doi.org/10.1021/acs.biomac.6b01396 
Reza M, Kontturi E, Jäskelainen A-S, Vuorinen T, Ruokolainen J (2015) Transmission electron microscopy for wood and fiber analysis - A review. BioResources 10:6230-6261.

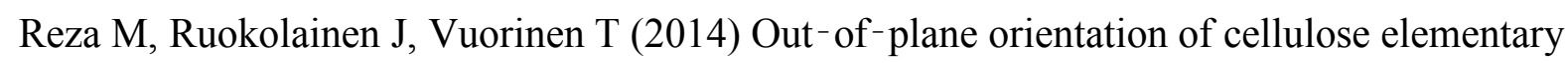
fibrils on spruce tracheid wall based on imaging with high-resolution transmission electron microscopy. Planta 240:565-573. https://doi.org/10.1007/s00425-014-2107-1

Robards AW, Sleytr UB (1985), in "Low Temperature Methods in Biological Electron Microscopy", Practical Methods in Electron Microscopy, Glauert AM ed, Elsevier, vol 10, chap 6, pp 309-459.

Roche E, Chanzy H (1981) Electron microscopy study of the transformation of cellulose I into cellulose III in Valonia. Int J Biol Macromol 3:201-206. https://doi.org/10.1016/0141-8130(81)90064-7

Saito T, Kuramae R, Wohlvert J, Berglund L, Isogai A (2013) An ultrastrong nanofibrillar biomaterial: the strength of single cellulose microfibrils revealed via sonication-induced fragmentation. Biomacromolecules 14:248-253. https://doi.org/10.1021/bm301674e

Saito T, Nishiyama Y, Putaux J-L, Vignon M, Isogai A (2006) Homogeneous suspensions of individualized microfibrils from TEMPO-catalyzed oxidation of native cellulose. Biomacromolecules 7:1687-1691. https://doi.org/10.1021/bm060154s

Schappacher M, Putaux J-L, Lefebvre C, Deffieux A (2005) Molecular containers based on amphiphilic PS-b-PMVE dendrigraft copolymers: topology, organization and aqueous solution properties. J Am Chem Soc 127:2990-2998. https://doi.org/10.1021/ja0440203

Skogberg A, Mäki A-J, Mettänen M, Lahtinen P, Kallio P (2017) Cellulose nanofiber alignment using evaporation-induced droplet-casting, and cell alignment on aligned nanocellulose surfaces. Biomacromolecules 18:3936-3953.

https://doi.org/10.1021/acs.biomac.7b00963

Stinson-Bagby KL, Roberts R, Foster EJ (2018) Effective cellulose nanocrystal imaging using transmission electron microscopy. Carbohydr Polym 186:429-438. https://doi.org/10.1016/j.carbpol.2018.01.054

Sugiyama J, Harada H, Fujiyoshi Y, Uyeda N (1985) Lattice images from ultrathin sections of cellulose microfibrils in the cell wall of Valonia macrophysa Kütz. Planta 166:161-168.

Sugiyama J, Harada H, Fujiyoshi Y, Uyeda N (1985) Observations of cellulose microfibrils in Valonia macrophysa by high resolution electron microscopy. Mokuzai Gakkaishi 31:61-67.

Sugiyama J, Otsuka Y, Murase H, Harada H (1986) Toward direct imaging of cellulose microfibrils in wood. Holzforschung 40 Suppl:31-36.

Sugiyama J, Vuong R, Chanzy H (1991) Electron diffraction study on the two crystalline phases occurring in native cellulose from an algal cell wall. Macromolecules 24:41684175. https://doi.org/10.1021/ma00014a033

Talmon Y (1987) Electron beam radiation damage to organic and biological cryospecimens. In Cryotechniques in Biological Electron Microscopy, Steinbrecht RA and Zieorld K eds, Springer-Verlag, Chapter 3, pp 64-84.

Tanaka R, Kuribayashi T, Ogawa Y, Saito T, Isogai A, Nishiyama Y (2017) Ensemble evaluation of polydisperse nanocellulose dimensions: rheology, electron microscopy, X-ray scattering and turbidimetry. Cellulose 24:3231-3242.

https://doi.org/10.1007/s10570-017-1334-6

Tibolla H, Pelissari FM, Martins JT, Vicente AA, Menegalli FC (2018) Cellulose nanofibers produced from banana peel by chemical and mechanical treatments: Characterization and 
cytotoxicity assessment. Food Hydrocoll 75:192-201.

https://doi.org/10.1016/j.foodhyd.2017.08.027

Usov I, Nyström G, Adamcik J, Handschin S, Schütz C, Fall A, Bergström L, Mezzenga R (2015) Understanding nanocellulose chirality and structure-properties relationship at the single fibril level. 6:7564. https://doi.org/10.1038/ncomms 8564

Wade RH (1984) The temperature dependence of radiation damage in organic and biological materials. Ultramicroscopy 14:265-270. https://doi.org/10.1016/0304-3991(84)90094-9

Walker M, Knight P, Trinick J (1985) Negative staining of myosin molecules. J Mol Biol 184:535-542. https://doi.org/10.1016/0022-2836(85)90300-6

Watt IM (1997) The Principles and Practice of Electron Microscopy. Cambridge University Press.

Zhang Y, Cheng Q, Chang C, Zhang L (2018) Phase transition identification of cellulose nanocrystal suspensions derived from various raw materials. J Appl Polym Sci 135:45702. https://doi.org/10.1002/APP.45702

Zoppe JO, Dupire AVM, Lachat TGG, Lemal P, Rodriguez-Lorenzo L, Petri-Fink A, Weder C, Klok H-A (2017) Cellulose nanocrystals with tethered polymer chains: Chemically patchy versus uniform decoration. ACS Macro Lett 6:892-897. https://doi.org/10.1021/acsmacrolett.7b00383

Zuluaga R, Putaux J-L, Cruz J, Vélez J, Mondragon I, Gañán P (2009) Cellulose microfibrils from banana rachis: Effect of alkaline treatments on structural and morphological features. Carbohydr Polym 76:51-59. https://doi.org/10.1016/j.carbpol.2008.09.024 